\title{
St. Gallen 2007 - Where Does It Lead Us?
}

\author{
Volker Hanf \\ Frauenklinik, Klinikum Fürth, Germany
}

I'm travelling back from St. Gallen thinking about what to report during the upcoming obligatory post St. Gallen conference at home.

Principally, I appreciate and enjoy that the program is built up systematically from basic breast cancer tumor biology through diagnostic procedures to primary and adjuvant therapy. Avoiding parallel sessions, the program gives a very good overview on up-to-date therapy. - Or it would, if I could only make sense of some of the lingo of individual American presenters that apparently feel so much at home at St. Gallen (good!) that they forget that most attendees are not native speakers (pity!). Knowing to be invited every next time over might also influence the individual strive for excellence in presentation. Not quite inappropriately Martine Piccart diagnosed 'a mess' in the data on an important burning topic and maybe the respective presentation.

The highlight of the conference, however, is expected to be found in the panel discussion, which gives the basis for the well reputed St. Gallen recommendations. The moderator initially warns that recommendations rather than guidelines are being sought, however, it has to be assumed that many attendees hold great belief in the knowledge of the distinguished panelists. The discussion is conducted in the form of a televoting quiz show; any answer is possible. For the audience this holds the prospect of entertainment, one can answer the ques- tions for oneself. Young doctors sitting for their board examinations can check their knowledge against the elite and will rarely be embarrassed: most of the crucial questions are answered as if flipping a coin, 50:50 is not a rare quota. Where does this lead us? It leads us away from evidence-based decision-making to a collection of individual opinions. Quite a proportion of the questions are answered by a significant quorum in contradiction to existing $\mathrm{S} 2$ and $\mathrm{S} 3$ guidelines (S2 and S3 guidelines are both evidence-based, S3 is the most advanced development requiring a formalized evidence evaluation, discussion and decision-making process).

As a member of the AGO Guidelines commission, for me personally, this consensus panel voting process casts light on the importance of our own strive for a balanced evaluation of the existing trial data. However exhausting the process each time over may be: the intense discussion on almost every single item, with the individual original paper on hand, trying to convince our fellow members in order to reach an evidence-based consensus, appears most worthwhile. Our recommendations, made ready for every day use by the addition of the practical AGO-Score $(++,+,+-, \ldots-)$ can advise the practicing breast care specialist. They are now also available in English (http://www.ago-online.com/index.php? site=mamma\& lang $=d e$ ) if the odd audience member coming home from St. Gallen should incidentally require some further guidance.

Volker Hanf, Fürth

\begin{tabular}{llll}
\hline KARGER & \multirow{2}{*}{ ( 2007 S. Karger GmbH, Freiburg } & & Prof. Dr. Volker Hanf \\
Fax +49 761 4 52 07 14 & Accessible online at: & Frauenklinik \\
E-mail Information@Karger.de & www.karger.com/brc & Klinikum Fürth \\
www.karger.com & & Jakob-Henle-Straße 1, 90766 Fürth, Germany \\
& & Tel. +49 911 7580-1301, Fax -1886 \\
& & E-mail volker.hanf@klinikum-fuerth.de
\end{tabular}

